\title{
Flexor digitorum profundus tendon avulsion in an amateur basketball player: Jersey finger
}

\author{
Sabit Numan Kuyubaşı, Alper Çıraklı, Eyüp Çağatay Zengin, Murat Erdoğan, Ahmet Pişkin \\ Departments of Orthopedics and Traumatology, Faculty of Medicine, Ondokuz Mayls University, Samsun, Turkey
}

\begin{tabular}{ll}
\hline ARTICLE INFO & ABSTRACT \\
\hline $\begin{array}{ll}\text { Article History } \\
\text { Received }\end{array} \quad 26 / 02 / 2013$ & $\begin{array}{l}\text { Flexor tendon injury of the finger may be open or closed, but it is not as common as } \\
\text { extensor tendon injuries. Pathogenesis is associated with many factors. Sports injuries } \\
\text { are also among those causes. Applied treatment approach is primary repair or pull-out } \\
\text { technique. In this paper, we discussed the case in the light of the literature, that we } \\
\text { performed repair via pull out technique for flexor digitorum profundus tendon avulsion } \\
\text { in an amateur sportsman. }\end{array}$ \\
\hline Correspondence to: & $12 / 03 / 2013$
\end{tabular}

\section{Sabit Numan Kuyubaşı}

Department of Orthopedics and

Traumatology, Faculty of Medicine,

Ondokuz Mayıs University, Samsun, Turkey

e-mail: s.numankuyubasi@hotmail.com

\section{Keywords:}

Flexor digitorum profundus

Avulsion

Sport injuries

Jersey finger

\section{Introduction}

Flexor tendon injuries of the finger may be open or closed. The most common among the close tendon injuries is flexor digitorum profundus (fdp) tendon avulsion (Nas, 2012). Common injury mechanism in close flexor tendon rupture occurs by sudden hyperextension of the finger while it is in active flexion (Simman and Fietti, 2000; Clavero et al., 2002). It is most commonly seen in physically active and young men during sport activities (Clavero et al., 2002). Diagnosis is often made by history, physical exam and radiologic evaluation (Leggit and Meko, 2006). In this paper, we presented two weeks-late diagnosed patient with flexor tendon injury during sport activity.

\section{Case}

Seventeen-years-old male patient referred to orthopedic clinic for limited motion in the fourth digit of the right hand. Anamnesis revealed that he had no previous diseases, suspended over the basket during basketball training approximately two weeks ago, referred to emergency service for pain and swelling in the fourth digit of his right hand and was applied analgesic medication since there was no fracture on X-ray. In physical exam, distal interphalangeal joint of the fourth finger was tender to palpation and active flexion motion was not observed (Fig. 1).
Neurovascular examination was normal. Obtained X-ray did not reveal any fracture. The patient was diagnosed with fdp tendon avulsion. $\mathrm{z}$ incision was performed from volar surface of fourth finger under general anesthesia. In deep dissection, it was observed that fdp tendon was detached and retracted proximal to the metacarpophalangeal joint level. Tendon repair was performed via pull-out technique. Short arm splint was used to stabilize. Passive flexion and extension exercises were started two days later. After three weeks the splint was removed and active and passive finger exercises were started (Fig. 2). At the end of the sixth week, finger functions were complete.

\section{Conclusion}

Fdp tendon avulsion is seen commonly in physically active young men during exercising (Clavero et al., 2002). First presentation places of patients are generally emergency services. Diagnosis is mostly made by history, physical exam and radiologic evaluation (Leggit and Meko, 2006). Due to swelling and pain, joint motions can not be evaluated appropriately. It must be kept in mind that tendon injuries might happen in the patients with normal X-ray. Functional findings might be affected in late diagnosis and treatment. If needed, orthopedics and traumatology division should be consulted. 


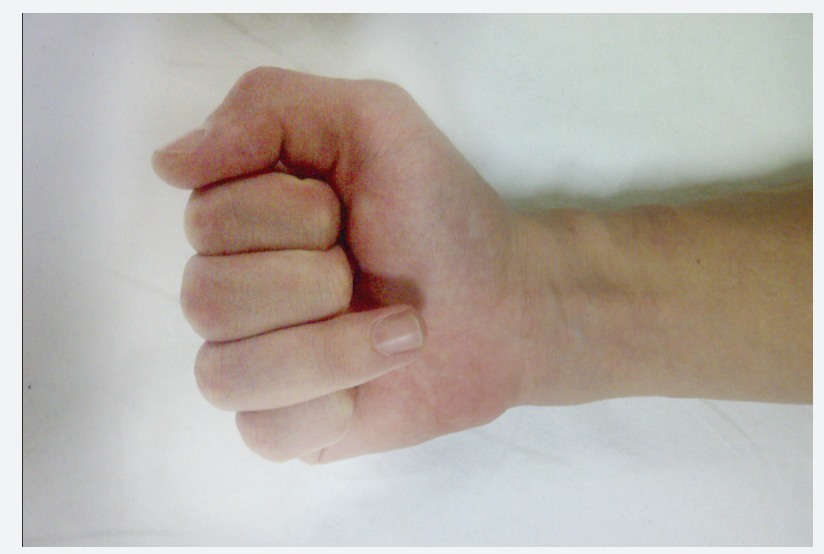

Fig. 1. Limitation of movement of the patient prior to surgery.

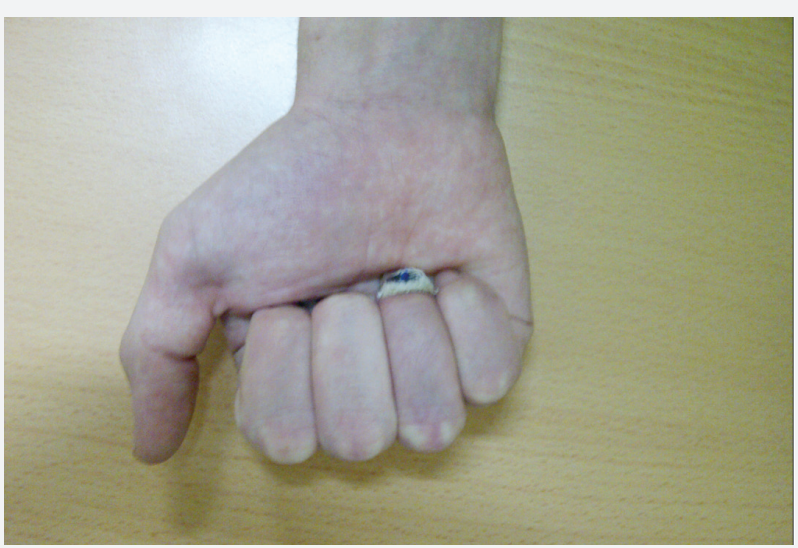

Fig. 2. Limitation of movement of the patient after surgery.

\section{REFERENCES}

Clavero, J.A, Alomar, X., Monill, J.M., Esplugas, M., Golanó P, Mendoza, M., Salvador, A., 2002. MR imaging of ligament and tendon injuries of the Fingers. RadioGraphics. 22, 237-256.

Leggit, J.C., Meko, C.J., 2006. Acute finger injuries, part I: Tendonsand ligaments. Am. Fam. Physician. 73, 810-816.

Nas, Ö.F., 2012. The Medical Bulletin of Şişli Etfal Hospital. 46, 221-224.

Simman, R., Fietti, V.G., 2000. Closed rupture of the flexor digitorum profundus tendon of the left little finger. Hosp. Physician. 36, 55-57. 